\title{
Methods and algorithms of food industry enterprises electrical energy consumption control
}

\section{Liudmyla Kopylova, Sergii Baliuta, Oleg Mashchenko}

\author{
National University of Food Technologies, Kyiv, Ukraine
}

\section{Keywords:}

Electrical

Energy

Control

Consumption

Food

Industry

\section{Article history:}

Received

24.09.2017

Received in revised

form 19.10.2017

Accepted

29.12.2017

\section{Corresponding author:}

Oleg Mashchenko

E-mail:

ol1973@ukr.net

DOI:

$10.24263 / 2310-$

$1008-2017-5-2-11$

\section{Abstract}

Introduction. The conducted researches of the food industry enterprise electrical energy consumption control with the aim of electrical resources efficiency increase by electricity consumption control methods and algorithms developing.

Materials and methods. The researches are made on the base of control processes system analysis methods.

Results and discussion. The analysis of the food processing enterprise (FIE) electrical energy consumption control has allowed to determine the main stages of the control process: the basic control functions are electric energy (EE) consumption registration, forecasting of $\mathrm{EE}$ consumption, calculation of $\mathrm{EE}$ consumption norms, consumers - regulators (CRs) list formation; control functions support conditions - EE consumption information, restrictions and rates, electricity consumption forecasting accuracy requirements; organizational and technical mechanisms of control functions implementation - information and computing system, electric power dispatcher, process operator, electrical supervisor; basic information flows which provide electrical energy consumption control - predicted temperatures values, EE consumption and production output current data, decisions settled on EE consumption. Represented methods and algorithms of FIE electrical energy consumption management with use of CRs. When creating a FIE EE consumption management forecasting mathematical model an artificial neural network in the form of a multilayer perceptron was used. In order to study the artificial neural network is used the combined training method based on the back error propagation method and the Cauchy method. The organizational and technical FIE EE consumption management requirements are formulated. It is determined that taking into account the technological process and the EE consumption process mutual connection for EE consumption control it is necessary to use a dialogue system.

Conclusion. FIE EE consumption control is realized with the use of forecasting values received via artificial neural network by the optimal EE consumers composition forming on the base of the heuristic algorithm. This allows to ensure the high efficiency and to take into account damages caused by CRs disabling. 


\section{Glossary}

ACSFIE - automated EE consumption control system of food industry enterprise; EE - electric energy;

FIE - food industry enterprise;

$\mathrm{CR}$ - consumer-regulator.

\section{Introduction}

The electric energy (EE) consumption reducing problem is relevant for the food industry, since it allows to increase the generating capacities use efficiency and to reduce EE consumption during its transmission and the energy intensity of production outputted by enterprises. For ensuring of rational EE consumption levels by food industry enterprises (FIE), it is necessary to forecast its consumption and use consumers-regulators (CRs).

The electric energy control issues are devoted a number of works [1-6]. Let us look at some of them. In the article [1] the software of commercial EE accounting systems and the technical facilities complex "Energomira" is represented. It is represented by the software modules set for the commercial EE accounting organization on energy sites. As such objects can be used energy companies, electricity grid areas, substations and other EE consumers.

The technical facilities complex "Energomira" software includes:

- automatic dispatcher workplace, which realizes the data processing from the data collection device and from data collection and transmission device, their representation in form of charts and tables;

- $\quad$ report generator for creating various documents forms;

- data collection and database development programs;

- technical facilities complex administering programs for the system devices parameters determining.

The works analysis $[1,2]$ showed that the software presented in them was created by various organizations, which did not interact with each other when it was created. This condition causes significant complications with this software sharing.

The article [3] represents a two-level automated EE consumption accounting system "E1 - Energy-accounting". The lower system level contains electronic counters "Euro Alpha" and "Alfa Plus" with digital communication channels, and the upper - modern computers with automatic dispatcher workplaces. The system is based on the client-server architecture. It allows to support an arbitrary number of client computers with automatic dispatcher workplaces. However, at present, this system solves only the EE accounting problems.

Recently, more and more automated new generation control and accounting EE systems are used, which are developed on the basis of modern industrial controllers [4]. These systems are aimed at solving the problems of commercial EE accounting and capacity consumption, as well as technical accounting and monitoring of industrial enterprises electrical loads in real time mode.

The works analysis [4-6] shows that the systems presented in them are performing functions of electric capacity and EE control. These systems do not realize the EE valuation, planning, forecasting and control optimization functions of industrial enterprises, which allows to obtain the main economic effect. 
The aim of the research consists in the automated synthesis of food industry enterprise EE consumption control and supply system on the base of the transmission control process systematic analysis, EE distribution and consumption.

\section{Materials and methods}

\section{Research materials}

The food industry enterprise electrical energy consumption control process is studied.

\section{Research methods}

Researches were conducted in the following order:

- $\quad$ it was made a systematic analysis of the electrical energy consumption process;

- $\quad$ it was developed the FIE electrical energy consumption control algorithm with the use of consumers-regulators;

- $\quad$ it was developed the mathematical model of electrical energy consumption forecasting with the use of an artificial neural network;

- $\quad$ it was developed the consumers-regulators choice;

- $\quad$ it is developed the electrical energy consumption automated control system on the basis of the forecasted values of the enterprise electrical energy consumption using the decision-making dialogue subsystem.

\section{Results and discussion}

The automated EE consumption control system of food industry enterprise (ACSFIE) is created with the purpose of the electric resources efficiency use increasing and the production energy intensity reducing due to the EE consumption predicted values use, EE consumption regulatory values, analysis of arising production situations and the assessment of production energy efficiency improving measures [8].

The system synthesis is based on the subsystem representation in the form of a interconnected structures set: decision making support, as well as, functional, organizational, technical and informational support.

Let us formulate requirements for creatable subsystem:

- $\quad$ efficiency (system construction and operation costs should be lower than the

- results obtained);

- $\quad$ adaptability (the system should be simple in construction and mastering);

- $\quad$ scalability (the ability to change the coverage breadth.

The enterprise EE consumption control process will be represented in the form of a interconnected depictions set:

$$
\begin{gathered}
\forall b_{n} \exists \chi_{n}\left(K_{n}, T_{n}\right): \quad P_{n} \rightarrow P_{n+1} \\
\mathrm{~B}_{1} \in \mathrm{B}=\left\{\mathrm{b}_{1}, 1=1, \ldots, \mathrm{L}\right\} ; \\
\mathrm{K}_{\mathrm{n}} \subset \mathrm{K}=\left\{\mathrm{k}_{1}, 1=1, \ldots, \mathrm{L}\right\} ; \\
\mathrm{T}_{\mathrm{n}} \subset \mathrm{T}=\left\{\mathrm{t}_{\mathrm{m}}, \mathrm{m}=1, \ldots,\right\} ; \\
\mathrm{P}_{\mathrm{n}}, \mathrm{P}_{\mathrm{n}+1} \subset \mathrm{P}=\left\{\mathrm{p}_{\mathrm{g}}, \mathrm{g}=1, \ldots, \mathrm{G}\right\}
\end{gathered}
$$


where $B$ means process stages of the EE consumption control: $b_{1}$ is the stage of registration and verification of the measurement information accuracy; $b_{2}$ is the stage of model choosing and enterprise EE consumption and production sections forecasting; $b_{3}$ is the stage of rationing and planning of enterprise and production sections electricity consumption on the base of forecast values, enterprise electric balance closing; $b_{4}$ is the stage of comparison of actual and planned enterprise EE consumption and production sections for a certain period and decision making on the enterprise EE consumption;

$\chi_{n}$ is the displaying function of the control process at the-stage $b_{n}$;

$K$ means realization conditions of all enterprise EE consumption control functions: $k_{1}$ are normative acts on EE consumption by consumers; $k_{2}$ are terms and conditions of the contract for FIE EE supply; $k_{3}$ are metrological requirements for EE accounting devices; $k_{4}$ are requirements for the accuracy of the EE consumption forecast;

$T$ means organizational and technical facilities and structures used for the control functions realization: $t_{1}$ is an information and computing system of electrical supervisor service; $t_{2}$ is an electric power dispatcher; $t_{3}$ is an electrical department; $t_{4}$ is electrical supervisor; $t_{5}$ are EE accounting sensors and measuring devices;

$P$ means input and output information streams used in the control process of FIE EE consumption: $p_{1}$ are average daily environment temperature data; $p_{2}$ are enterprise and production sections EE consumption data; $p_{3}$ are data on production volumes produced by the enterprise; $p_{4}$ are enterprise EE consumption limits; $p_{5}$ is a reliable information about the average environment daily temperature; $p_{6}$ is a reliable information about the enterprise and production sections EE consumption; $p_{7}$ and $p_{8}$ are forecast and planned values of production sections EE consumption; $p_{9}$ are decisions made to control the enterprise EE consumption.

Taking into account the introduced symbols, the displaying functions of the FIE EE consumption control process will take such the form:

for the stage $b_{1}$ - the stage of registration and verification of the measurement information accuracy used by FIE EE consumption control:

$$
\chi_{1}\left(k_{3}, t_{1}, t_{2}, t_{5}\right):\left(p_{1}, p_{2}\right) \rightarrow\left(p_{5}, p_{6}\right) ;
$$

for the stage $b_{2}$ - the stage of model choosing and enterprise EE consumption and production sections forecasting:

$$
\chi_{2}\left(k_{1}, k_{4}, t_{1}\right):\left(p_{3}, p_{5}, p_{6}\right) \rightarrow p_{7}
$$

for the stage $b_{3}$ - the stage of rationing and planning of enterprise and FIE production sections electricity consumption on the base of their forecast values :

$$
\chi_{3}\left(k_{1}, t_{1}, t_{2}\right):\left(p_{3}, p_{7}\right) \rightarrow p_{8} ;
$$

for the stage $b_{4}$ - the stage of comparison of actual and planned enterprise EE consumption and production sections for a current month; decision making on the enterprise EE consumption control:

$$
\chi_{4}\left(k_{1}, k_{2}, t_{1}, t_{2}, t_{3}, t_{4}\right):\left(p_{4}, p_{6}, p_{8}\right) \rightarrow p_{9} .
$$


Interaction between the control process stages is realized with help of information flows.

\section{Planned electric energy consumption control}

The capacity planning of the FIE consumer used in the FIE is conditioned by the need to determine the possibility of load regulation in the normal mode in order to minimize the EE consumption and to identify the EE consumers-regulators in the normal mode $\left(\mathrm{CRs}_{\mathrm{N}}\right)$ and in the forced mode, which is implemented when restrictions from the direction of the the EE supplying organization are used (definition of consumers-regulators of EE in the forced mode $\left.\left(\mathrm{CRs}_{\mathrm{F}}\right)\right)$ [3].

The classification and determination of the EE consumers-regulators formation criteria is given in [7]. Enterprise EE consumption by the technological process load regulation of consumers with the help of this process moving into energy systems minimal loads zones is proposed in work [8].

The transfer of EE consumers to the consumers-regulators mode is realized in accordance with the formalized target functions and restrictions that correspond to them, as well as taking into account the CRs $\mathrm{CRs}_{\mathrm{j}}^{\mathrm{i}}$ type and work mode (see Table 1).

Table 1

\begin{tabular}{|c|l|c|c|}
\hline Target function & \multicolumn{1}{c|}{$\begin{array}{c}\text { Target function } \\
\text { restrictions }\end{array}$} & CRs type & $\begin{array}{c}\text { Work } \\
\text { mode }\end{array}$ \\
\hline$W_{L} \rightarrow 0$ & $\left\{\begin{array}{l}E_{\text {addit. }}=0, y=0 \\
E=E_{\text {norm. }}, y=0\end{array}\right.$ & $C R_{N}^{I}$ & Normal \\
\hline$W_{L}-W_{\text {allwb. }} \rightarrow 0$ & $\left\{\begin{array}{l}E_{\text {addit. }}=0, y=0 \\
E \geq E_{\text {norm. }}, y=0\end{array}\right.$ & $C R_{N}^{I I I}$ & Normal \\
\hline$y \rightarrow \min$ & $W_{L}<W_{\text {allwb. }}, E>E_{\text {norm. }}$ & $C R_{N}^{I V}$ & \\
\hline
\end{tabular}

In this table: $W_{L}$ means CRs electricity consumption peak load; $W_{\text {allwb. }}$ means allowable CRs EE consumption in peak load; $E_{\text {addit. }}$ means additional expenses for the off-peak work mode creation; $y$ means the damage of the enterprise from the CRs off-peak work mode organization; $E$ and $E_{n o r m}$. mean calculated and normative efficiency coefficients.

\section{Algorithm of food industry enterprise electric energy consumption}

The satisfaction of the electric energy system EE consumption volumes requirements and ensuring of the normative FIE EE consumption level with a minimal expenses for FIE is achieved by changing the work mode of the CRs energy consuming equipment (shutdown or transfer to a reduced work mode). The following algorithm of industry enterprise EE consumption control is proposed (Fig. 1). 


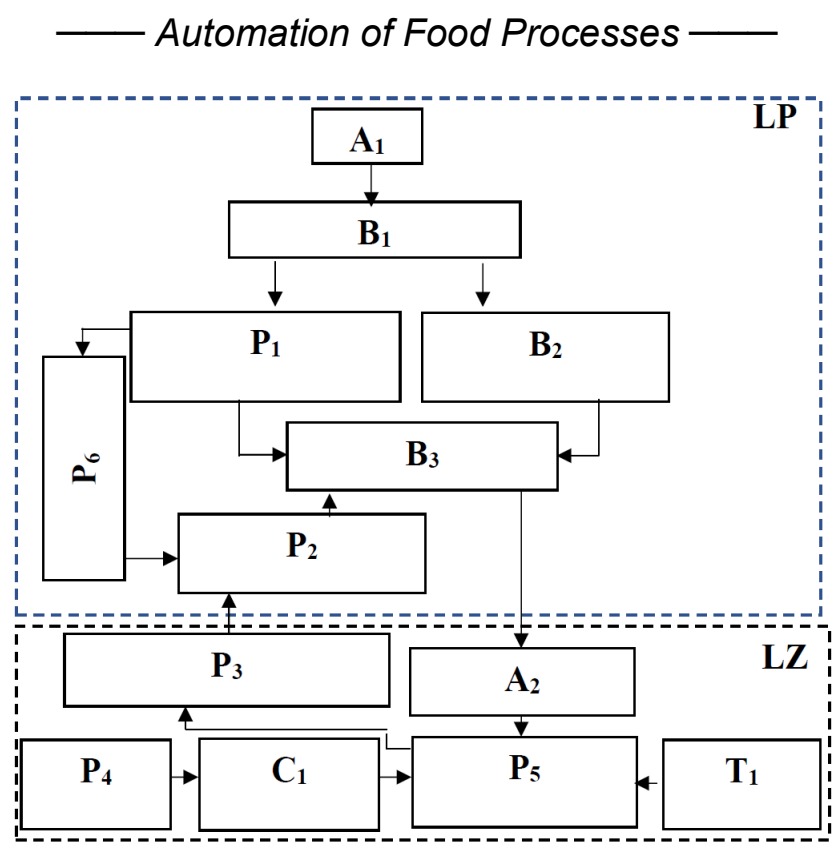

Figure 1. Algorithm of FIE EE consumption control with use of CRs

$\mathrm{A}_{1}$ means of EE consumption data analysis; $\mathrm{A}_{2}$ is EE consumption restrictions analysis; $\mathrm{B}_{1}$ is of the share determination of each consumer in the total EE consumption; $\mathrm{B}_{2}$ is consumers-regulators identification; $\mathrm{B}_{3}$ is the $\mathrm{EE}$ consumption restriction setting; $\mathrm{P}_{1}$ is $\mathrm{EE}$ consumption and $\mathrm{EE}$ consumption norms forecast; $\mathrm{P}_{2}$ means comparison of fines and damages amount comparison; $\mathrm{P}_{3}$ is damages results calculation; $\mathrm{P}_{4}$ is energy inspections conducting; $\mathrm{C}_{1}$ is damages database creation; $\mathrm{P}_{5}$ means electrical receivers selection and damages estimation in case of their disabling; $\mathrm{P}_{6}$ is energy system fines calculation; $\mathrm{T}_{1}$ means technological restrictions; LP is enterprise level; LZ is section level.

In the normal work mode after fixed time intervals $\Delta t$ from the initiative of information and computing system of the EE consumption control subsystem upper level is conducting the counters survey of automated EE consumption and calculation system, determination and calculation of actual current EE consumption by lower level elements of the EE consumption mode control system. Decisions are made depending on the forecasted value of EE consumption $W_{\text {forca }} \in W$.

The set of possible $W$ values of EE consumption is divided into a range of disjoint subsets:

$$
M_{1}=\left\{W_{\text {forca }} \geq W_{L}^{U}\right\} ; M_{2}=\left\{W_{L}^{L}<W_{\text {forca }}<W_{L}^{U}\right\} ; M_{3}=\left\{W_{L}^{L} \geq W_{\text {forca }}\right\}
$$

where $W_{L}^{L}, W_{L}^{U}$ mean lower and upper EE consumption restriction.

Each of the selected subsets corresponds the set of controlling influences. As a EE consumption amount restriction, the FIE stated maximal EE consumption for this month $W_{\max }^{k}$ or the more stringent restrictions placed by energy system in the case of the scarce fuels absence, emergency situations, and so on.

The hit of a controlled parameter $W_{\text {forc. }}$ in each of the selected subsets $M_{1}, M_{2}, M_{3}$ leads 
to the corresponding control influence formation.

As it follows from the given above procedure, the EE consumption mode control is leaded to:

- problems solving of EE consumption forecast and optimal CRs composition choosing (the upper level of the EE consumption mode control subsystem);

- problem solving of selected objects within a given frames during the accounting period EE consumption support (lower level of the of the EE consumption mode control subsystem).

As already was noted, the EE consumption forecast should be realized at the upper level of the of the of the EE consumption mode control subsystem with the view of possible fines determination from the energy systems and the EE consumption normalized values comparison.

The FIE EE consumption control is realized with use of EE consumption forecast values for specified times moments with the view of energy-efficient EE consumption modes providing and the energy system requirements fulfill on account of EE consumption restriction during maximal load periods. For control functions realization are used: the EE consumption forecasting model of, EE consumption control decisions making algorithms, the CRS optimal list formation and rational EE consumption modes formation.

\section{Mathematical model of the food industry enterprise EE consumption forecasting on the base of artificial neural network}

The base for any forecasts constructing, including the EE consumption forecast, is a mathematical forecast model.

The process of the forecast model building includes following steps:

- the forecasting method choice, which determines the forecast model

- essence;

- input and output model parameters choice;

- formation, training and verification of the data set accuracy;

- the forecast model internal structure construction, which determines the

- dependence of the output parameters from the input ones;

- the forecast model verification and the quality estimation of the received forecasts.

As a forecasting method during the forecast model constructing of the FIE EE consumption, it will be used forecasting on the base of artificial neural networks. This will increase the adaptability degree of the obtained model, achieve a good generalizing ability and provide the possibility of complex nonlinear dependencies setting of the output parameters from the input ones [9].

The output parameter of the forecast model will be used the hourly EE consumption $\mathrm{W}_{\mathrm{h}}$ of the enterprise as a whole.

Let us conduct the parameters analyze that affect the FIE EE consumption at various levels of its energy supply system.

FIE energy supply work mode is characterized by the following parameters:

- active, reactive capacity and EE consumption of electrical receiver that are used for balance compilation;

- voltage in the FIE electric network nodes;

- currents in EE transmission lines;

- wastes in EE transmission lines;

- EE quality Indicators. 
The main, basic parameters of FIE energy supply system work mode are the capacity consumption and EE. Depending on the capacity consumption, in the nodes of the system will change the voltage, and in the lines - currents. The FIE EE amount consists of the EE consumption $w_{i}$ of all $\mathrm{N}$ of all electrical receivers working at current time and EE wastes $\Delta W$ in the network elements:

$$
W=\sum_{i=1}^{N} w_{i}+\Delta W
$$

EE wastes, in their turn, in the energy supply systems main elements: lines and transformers, will depend on the electrotechnical parameters of these elements themselves (their active and reactive resistances) and the energy transmitted with their help:

$$
\Delta W=f\left(W_{a}, W_{p}, R, X\right)
$$

In the energy supply work process, the resistances of its elements can be considered almost unchanged. Thus, a change of the current capacity waste in the enterprise network will occur due to changes in the total capacity of the electrical during their switching on, switching off or work mode change.

The EE consumption $w_{i}$ of each electrical receiver or group of ones, in their turn, can be written as follows:

$$
w_{i}=f\left(\lambda_{1}, \lambda_{2}, \ldots, \lambda_{n}\right)
$$

where $\lambda_{1}, \lambda_{2}, \ldots, \lambda_{n}$ are parameters, which influence on EE consumption.

The number of electrical receivers (primarily asynchronous and synchronous motors) at an enterprise can reach hundreds and thousands. For each electrical receiver, parameters that influence its EE consumption can be different.

It is not possible to construct FIE EE consumption forecast models that takes into account the parameters, which influence the EE consumption of each electric receiver because of the large number of interconnected input parameters in such a model. The most optimal is the electrical receivers combination in groups by any features (technological, electrical), with subsequent parameters identification that influence the EE consumption of each group. In their turn, the electrical receivers influential parameters totality of each group will be an input parameters set for the forecast model of the enterprise EE consumption as a whole.

In the general case, all electrical receivers, according to their purpose, can be divided into two groups:

- the main ones, which involve in the main production process of the enterprise. These electric receivers include electrotechnological devices (electrothermal and welding apparatuses, electrolysis baths), compressors, pumps and centrifuges drive, conveyors and other transport vehicles drive, metalcutting, woodworking and other machines, etc.

- auxiliary - that means such, which do not participate in the main enterprise production process. These include electric receivers, which are involved in the enterprise creation and support microclimate (ventilation and air-conditioning devices, air heaters), lighting devices and electrical receivers work on the enterprise sanitary and technical needs (pumps for cold and hot water supply, sewage, waste, etc.).

In their turn, electrical receivers of the main group can be grouped according to one or another area, section, production line. 


\section{Choice of structure, input parameters and methods of an artificial neural network training}

In this work for the FIE EE consumption forecasting from the artificial neural network architectures set was chosen multi-layered perceptron, first proposed by Frank Rosenblatt (1957), and later generalized by David Rumelhart (1986) [9].

This choice is caused by the possibility of complex nonlinear extrapolation problems solving in spite of the relative simplicity of the perceptron.

\section{Perceptron configuration selection}

As the input and output perceptron layers dimensions determining were based the following considerations:

- the input layer contains the number of elements (neurons) that corresponds to the retrospective data total number, which include daily EE consumption and average daily temperature for the working year days, that is previous to that for which is made the forecast, as well as the volumes change coefficient of enterprise manufactured production for the previous year;

- $\quad$ the output layer contains elements (neurons) that determine the predicted values of EE consumption.

The change coefficient of volumes outputted by the enterprise production is calculated on the basis of the proportion

$$
K_{\text {forc } i}=\frac{\Phi_{l}}{\Phi_{l+1}},
$$

where $\Phi_{l}$ means the production volume outputted in 1 year.

The choice of the intermediate (hidden) layers number and elements in them was conducted experimentally in such a way that for the various input and output data sets the minimum forecast error was reached.

It is determined that for EE consumption forecasting it is expedient to use one hidden layer with the number of elements equal to the half-sum of the input and output layers elements of the perceptron

$$
n_{H}=\left[\left(n_{X}+n_{Y}\right) / 2\right] \text {, }
$$

where $n_{H}$ means number of elements in the hidden layer, and $n_{X}$ and $n_{y}$ mean number of elements in input and output perceptron layers.

The set of perceptron weight coefficients is represented by a synoptic map $W$, the weight of the relationship between each neuron of the neighboring layers is indicated as $w_{i j}^{1}, w_{i j}^{2}$, where $i, j$ mean ordinal numbers of the neurons in the initial and final layers. Input values of daily EE consumption and average environment daily temperature for the last year are initialized as $W_{1}, \ldots, W_{N}$ and $T_{1}, \ldots, T_{N}$ correspondingly, as well as the output signals of the artificial neural network, the corresponding predicted values of EE consumption are indicated as $Y_{1}^{\prime}, \ldots, Y_{N^{\prime}}^{\prime}$.

The EE consumption accuracy forecasting of industrial enterprises depends to a great extent on the retrospective sample volume, which is used for perceptron training. The conducted studies have shown that for the required forecasting accuracy the retrospective 
sample volume of enterprise EE consumption and meteorological data for a period of four years is sufficient.

A retrospective sample of the FIE EE consumption values includes a sequence of training images pairs $L^{m}\left(K^{m}, Y_{b}^{m}\right)$ :

- $\quad K^{m}=\left[W_{1}^{j}, \ldots, W_{k}^{j}, T_{1}^{j}, \ldots, T_{k}^{j}\right]$ is input data vector, which are applied to the perceptron input (input signals);

- $\quad Y_{b}^{m}$ is vector of desired predictive values for $L^{m}, m=1,2, \ldots, N \quad(N$ is training data sets number).

When constructing the input vector $I$ of the retrospective sample, all daily EE consumption values, daily average temperature and illumination for each working day preceding the forecasted year are taken into account.

At perceptron output, the predicted value $W^{I}$ for $I$ input signals vector determines the predicted values of the enterprise EE consumption for the next year.

In connection with the conditions change of enterprise EE consumption, parameters of the forecasting model require an adaptation, which is realized at the end of the year and is accompanied by the perceptron re-training procedure, taking into account new retrospective data.

Using of unnormalized input data can cause the "saturation effect" on conditions which the element (neuron) of the perceptron is sensitive to the input values that are situated in the restricted area, that leads to its inadequate work. For the input data normalization is used the following formula

$$
P_{m}^{H}=\left(P_{m}-P_{\min }\right) /\left(P_{\max }-P_{\min }\right),
$$

where $P_{\min }$ and $P_{\max }$ are minimal and maximal value of input data in this sample, as well as $P_{m}$ and $P_{m}^{H}$ are nonnormalized and normalized values that are applied to $m$ perceptron entrance.

The perceptron behavior, in addition to the values of weight coefficients, also significantly depends on the type of activation function, transforming the input signal of the neuron into the output one.

As activation is selected the sigmoidal function

$$
f(u)=1 /\left(1+e^{-a u}\right) \text {, }
$$

where $a$ is an neuron parameter.

The sigmoidal activation function choice is caused by such fact that this function has continuous derivatives that are required for the back error propagation algorithm and that amplifies the weak signals to a greater extent than the strengths ones, what is important by high forecast accuracy.

For the adequate work of an artificial neural network is important its training algorithm, from which largely depends the network ability to solve given tasks.

The perceptron quality assessment is realized by the ratio:

$$
\varepsilon=\sum_{i=1}^{R} \varepsilon^{j} ; \quad \varepsilon^{j}=\left|Y_{n p}^{j}-Y^{j}\right|
$$

where $\varepsilon$ is training error, as well $\mathrm{as}^{j=1} \mathrm{Y}_{\text {forc. }}^{\mathrm{j}}$ and $Y^{j}$ are values of forecasted and actual perceptron exits.

The training process is completed if the error $\varepsilon$ for the whole set of input signals does not go beyond the set value $\varepsilon \geq 0$ or reaches a predetermined training iterations number. 
The perceptron training is realized by one of the fastest algorithms - an algorithm of back error propagation, which bases on the gradient descent method.

For adjusting of weight coefficients was used the expression

$$
\Delta w_{l m}^{(k)}=-\zeta \partial \varepsilon / \partial w_{l m},
$$

where $w_{l m}$ is the synaptic connection weight coefficients between $l$ neuron of $k-1$ layer and $m$ neuron of $k$ layer; $\zeta$ is rate training coefficient.

Despite such fact that the back error propagation method is widely used by the artificial neural network training, it has a significant disadvantage - it cope poorly with local minima [10], what can lead to their work deterioration. For exit from local minima is used a statistical training method - the Cauchy machine [9], by use of which a random change of the artificial neural network weight coefficients is conducted. However, this method is not effective because of slow convergence, since many steps of its realization are performed in the wrong direction.

The combination of the above examined method (algorithm) of the back error propagation with the Cauchy method (algorithm) allowed to obtain a combined training algorithm, which quickly finds the global training error minimum.

The trained perceptron allows not only to distinguish input data from the training sample, but also it is able to interpret the trends change in the forecasted process.

The FIE EE consumption mode control system on the base of the predicted values of electricity consumption is two-level:

- $\quad$ upper level (level of the main stepdown substation or input to the enterprise);

- lower level (EE consumer level).

For a compact description of this structure, the 1st level elements set will correspond certain numbers set of a natural sequence, which we shall call a 1 st level indices set $L_{1}=\{1,2, \ldots, i, \ldots, m\}$. It characterizes the presence of the upper level elements number (for example, substations), which are parts of contractual relations with the energy supply organization.

The 2nd level elements set will correspond the certain natural sequence number set, which we call a 2 nd level indices set $L_{2}=\{1,2, \ldots, i, \ldots, n\}$. Elements of this level relate only to certain elements of the upper level. For example, to the concrete substation concern only those consumers, who receive energy supply from this substation.

The EE consumption mode control system state at each of the fixed time moments $t=k \Delta t, \quad k=0, \ldots, K$ ( $\Delta t$ is the interval of input information into a computer complex) can be characterized by a set of parameters

$$
X=\left(W_{11}, \ldots, W_{m_{n} n}, \Delta W, z_{11}, \ldots, z_{m_{n} n}, k_{11}, \ldots, k_{m_{n} n}\right), x \in X,
$$

where $X$ is space of possible energy supply system states; $W_{i j}$ is consume of $i$ CR of $j$ level; $\Delta W$ is the load excess value set by the energy system restriction; $y$ is the CR specific damage estimation from changes in its work mode (damage per time unit), what includes fee for funds and depreciation deductions for equipment, which is disconnected, costs for capacity payment and damages from the technological process violation [8]; $k_{i j}$ is Boolean function equal to 1 , if the influence on the $\mathrm{i} C R$ of $\mathrm{j}$ level is exerted, and 0 is in other case.

Realization of control effects, which are implemented on the parameters set, is aimed 
at the minima achieving:

- damages from changes in the CR work mode and deviations from the EE consumption normative values;

- fines from energy systems, in case of over contract EE consumption;

- fines from energy systems, in case of underrated EE consumption compared with the contractual EE consumption amount.

FIE EE consumption control is conducted by optimal consumers composition forming.

In systematic EE consumption reduction can not participate CRs, disconnection of which is unacceptable for safety reasons, catastrophic consequences or can lead to significant damages and equipment failure as a result of changes in technological production processes. All other consumers can be used for regulation.

When choosing of $\mathrm{CR}$, is made their quality assessment for EE consumption regulation according to the vector criterion

$$
F(x)=\left[F_{1}(x) F_{2}(x)\right],
$$

defined in the states system space $X$ with the components

$$
F_{1}(x)=\sum_{j=1}^{n} \sum_{i=1}^{m_{j}} y_{i j} k_{i j}, F_{2}(x)=\sum_{j=1}^{n} \sum_{i=1}^{m_{j}} k_{i j}
$$

where $y_{i j}$ means the damage from use for the regulation of $i \mathrm{CR}$ at the $j$ level energy supply system; $k_{i j}$ is Boolean variable, which takes the value: -1 , if $i \mathrm{CR}$ of the $j$ level is used for load regulation and 0 is used in other case; $n$ is the consumers number allocated for regulation at the $j$ level.

CRs composition optimization is conducted in the region

$$
\sum_{j=1}^{n} \sum_{i=1}^{m_{j}} P_{i j} k_{i j} \geq \Delta P
$$

$\mathrm{CR}$ composition forming for active load regulation is realized on the base of problem solving of integer programming with Boolean variables with use of the heuristic algorithm. The consumers choice for the load regulation is realized from the very top level, which contains at least one consumer with a load that is less than that, which is stepped down.

Optimization at $j$ level was realized according to the criterion

$$
\sum_{i=1}^{m_{j}}\left(y_{i j} / W_{i j}\right) k_{i j} \rightarrow \min
$$

where $W_{i j}$ is EE consumption of $i$ consumer of $j$ level of energy supply system.

As the task restriction is used the load amount restriction, that is stepped down at this level.

$$
\sum_{i=1}^{m_{j}} P_{i j} k_{i j} t \geq \Delta W
$$

We use the heuristic algorithm of CR selection, according to which consumersregulators of $j$ level of the electrical network are arranged in order of the ratio increasing $y_{i j} / P_{i j}$. The target function minimization is realized by CR successive selection, from the received series, till load restriction violation. After task completing at the $j$ level, the last consumer from the selected ones is rejected. At the same time, load restriction is violated. The load value reduces by the total capacity amount $\Delta P$, which will remain in the CR list and the list formation at the $j+1$ level. If the further descent by levels is not possible, then 
the last of the rejected CRs is included in the list, and the algorithm work ends.

The CR choice at the enterprise network level is also conducted with help of the heuristic algorithm [8]. At the same time, for the network $j$ level, for which the problem is solved, are given the following data: the electrical equipment units number at this level and the load reducing value $\Delta P$. Prior also are calculated damages $y_{i j}$ and are determined the current CR electrical loads $-P_{i j}$.

This algorithm allows to get the set task solution by relatively simple mathematical methods. He realized the CR choice at network individual levels with the help of an approximate method. By insignificant costs for realization, it is characterized by certain wastes of accuracy load, which is switched off.

\section{Automated EE consumption control system construction on the base of predicted values of the enterprise $\mathbf{E E}$ consumption}

ACSFIE is a interacting units set - forecasting, regulation and EE consumption planning, the optimal consumers composition forming and the decision-making dialogue subsystem of the enterprise EE consumption control (Figure 2).

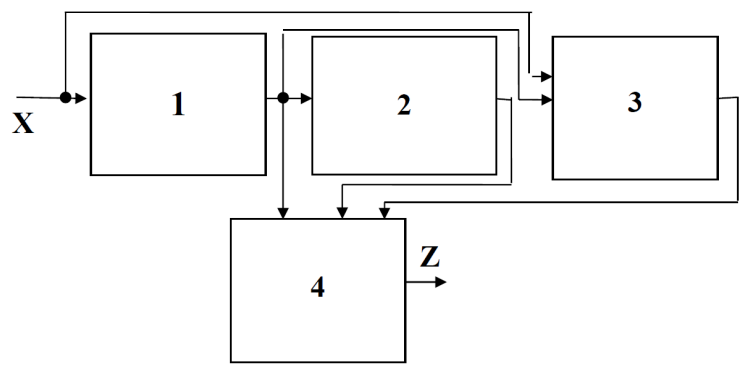

Figure 2. FIE automated EE consumption control system structure

$\mathbf{X}$ means input data; 1 is EE consumption forecasting unit; 2 is EE consumption expenses normalization and planning unit; 3 is forming unit of the optimal EE consumers composition; 4 is the dialogue support and decision-making subsystem; $\mathbf{Z}$ - control actions.

Let us consider the features and appointment of individual functional units Forecasting unit. On the basis of coming data from the databases for the EE expenses control, with the help of a three-layered perceptron, the EE consumption forecasting of the enterprise production units and the enterprise as a whole is realized. The predicted EE consumption values by data of these objects come to the EE consumption normalization and planning unit.

EE consumption regulation and planning unit. On the base of the obtained predicted values are determined the total expense norm and total planned EE expenses for production sections, as well as the expense norm and planned EE expense for the enterprise as a whole.

The obtained data are contained in the EE expense control databases. It also contains calculated on their base total planned EE expenses for non-production enterprise subunits.

The ACSFIE presence allows automatic and promptly compilation of annual, quarterly and monthly electrical balances of the enterprise and of the most energy-intensive installations and production subunits (sections). 
On these balances base is performed an analysis of the EE consumption, are identified economy directions, opportunities for unproductive $\mathrm{EE}$ expenses and wastes reducing of $\mathrm{EE}$ and are taken measures for its consumption improving.

\section{Optimal EE consumers composition forming unit}

On the base of the information coming from the EE expenses control databases, as well as the requirements of the energy system, is formed the CRs list, which will ensure the energy system requirements compliance relative to the EE consumption. The CRs list and EE consumption volumes are transmitted in the decision-making support subsystem.

\section{EE consumption decision-making control support subsystem}

From the databases of EE expense control are received data of the actual and planned EE consumption of production subunits and the enterprise as a whole, as well as the optimal EE consumers composition.

With help of the decision-making control support subsystem is realized a comparison of the actual and planned EE consumption values of the enterprise and production subunits, the results of which are proposed solutions for the EE consumption control of an industrial enterprise, which will ensure the use of the energy system requirements.

Appropriate decision variants (control influences), which represent the organizational and technical measures set aimed at the EE consumption plans correcting of the enterprise and production subunits during the period, that remains till the end of the year, are transmitted to the person, who is makes decisions and forms the final control influences.

At the end of the calendar year, is conducted the reasons analysis for EE consumption plans exceeding of production subunits and are taken measures for their prevention.

The general scheme of the decision-making process with use of the decision-making support dialogue subsystem is presented in Figure 3

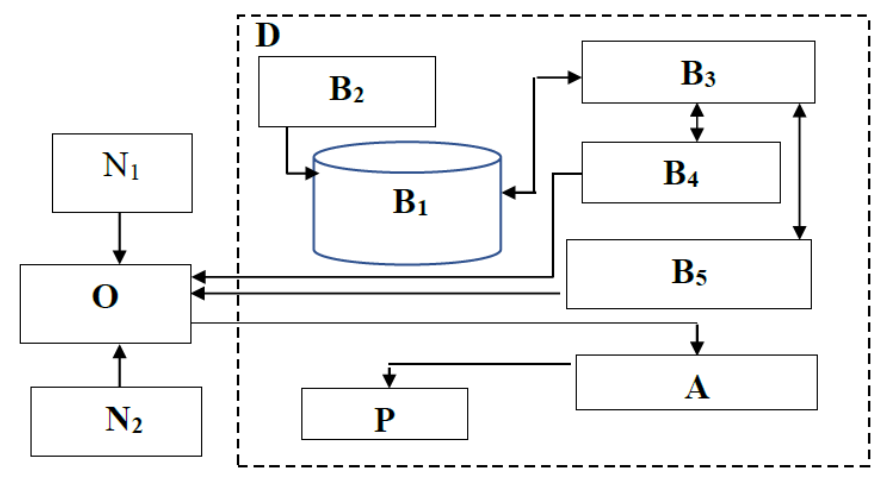

Figure 3. General scheme of the decision-making process of FIE EE consumption control with use of the dialogue subsystem

$\mathrm{N}_{1}$ means normative data for decision-making: energy system requirements for the $\mathrm{EE}$ consumption volumes; duration of the production program; optimal EE consumption norms; financial expenditures on $\mathrm{EE}$ for the production program realization; $\mathrm{N}_{2}$ is nonformalized criteria that take into account the specifics of a particular production and the 
current situation in the internal and external environment; $\mathrm{O}$ is the person, who makes decision; $\mathrm{D}$ is the decision-making support dialogue subsystem of FIE EE consumption control; $\mathrm{B}_{1}$ means the $\mathrm{EE}$ consumption database; $\mathrm{B}_{2}$ is the EE consumption automatic information collection unit; $\mathrm{B}_{3}$ is the interaction unit; $\mathrm{B}_{4}$ is $\mathrm{EE}$ consumption forecasting and normalization unit; $\mathrm{B}_{5}$ is the optimal $\mathrm{EE}$ consumers composition unit; A means the analysis of the production program variants and CRs; $\mathrm{P}$ is accepted CRs list and the production program variant.

\section{Organizational and technical support of enterprises EE consumption control.}

For the ACSFIE building are used modern information technology. The methods analysis of the automated control systems constructing has shown that it is expedient to realize the FIE EE consumption control on the platform of the general operating system, rather than the real-time operating system, since ACSFIE includes many "background" tasks, which are rigidly unrelated with the time of the solution: electric balance calculation tasks, normalization and planning of enterpises EE consumption and others.

Functions related with the information collection and its initial processing, are realized, as a rule, with help of programmable logic controllers. They are programmatically compatible with the MS Windows platform and are hosted on control points. Information from them is entered into personal computer.

\section{Conclusion}

The system analysis of the FIE EE consumption control process on the base of control process decomposition, allowed to determine the main control process stages; control functions conditions ensuring; organizational and technical mechanisms of the control functions realization; basic information flows, which provide EE consumption control.

When creating a mathematical forecasting model of the FIE EE consumption it is advisable to use a multilayer perceptron, which trains on the base of the back error propagation method and the Cauchy method. The FIE EE consumption volumes can be changed by forming of optimal consumers composition based on the heuristic algorithm with the use of the decision-making support dialogue subsystem.

The EE consumption control of food industry enterprises should be based on the EE consumption forecasting with help of the multilayer perceptron. Optimal EE consumption volumes can be achieved by forming of the consumers-regulators optimal composition on the basis of the heuristic algorithm with the use of the decision-making support dialogue subsystem.

\section{References}

1. Mirzoian Iu. T. (2000), Programmnoe obespechenie KTS «Energomera», Energetik, 8, pp. 42-44.

2. Kapitonova B. Tuganov V. Satarov L. (1996), Territorialno-raspredelennaia avtomatizirovannaia sistema ucheta i kontrolia elektropotrebleniia, Sovremennye tekhnologii avtomatizatsii, 1, pp. 78-80.

3. Bulaev Iu.V., Tabakov V.A., Eskin V.V. (2001), Kompleksnaia avtomatizatsiia energosnabzheniia predpriiatiia,Promyshlennaia energetika, 2, pp. 11-15. 
4. Egorov V.A. (2001), ASKUE sovremennogo predpriiatiia, Energetik, 12, pp. 41.

5. Kovezev S. N., Urazov B.V., Chumakov V.V. (2001), Sozdanie ASKUE na baze IVK «Sprut», Energetik, 2, pp. 11-13.

6. Molokan E. (1996), Avtomatizatsiia ucheta energopotrebleniia, Sovremennye tekhnologii avtomatizatsii, 1, pp. 74-76.

7. Prakhovnik A.V., Rozen V.P., Degtiarev V.V. (1985), Energosberegaiushchie rezhimy elektrosnabzheniia gornodobyvaiushchikh predpriiatii, Nedra, Moscow.

8. Rezchikov A.F., Ivashchenko V.A. (2008), Upravlenie eeektropotrebleniem promyshlennykh predpriiatii, Saratov.

9. Du K.-L., Swamy M.N.S. (2014), Neural networks and Statistical Learning, Springer.

10. Ben Krose, Patrick van der Smagt (1996), An introduction to Neural Networks, The University of Amsterdam.

11. Rodrigues P. P. (2009), A system for analysis and prediction of electricity-load streams, Intelligent Data Analysis, 13, pp. 477-496.

12. Anatoly Zamulko, Yurii Veremiichuk (2014), Methods of controlling power consumption in terms of reforming market conditions, Scientific Journal of Riga Technical University Power and Electrical Engineering, 32, pp. 41-45.

13. Auffhammer M., Blumstein C., Fowlie M. (2007), Demand-Side management and Energy Efficiency revisited, Berkeley. 